\title{
Poly(\&-caprolactone) films reinforced with chlorhexidine loaded electrospun polylactide microfibers
}

\author{
Y. Márquez ${ }^{1,2}$, J. Graupera ${ }^{1}$, L. J. del Valle ${ }^{1}$, P. Turon $^{2}$, L. Franco $^{1}$, J. Puiggali $^{1 *}$ \\ ${ }^{1}$ Departament d'Enginyeria Química, Escola d'Enginyeria de Barcelona Est-EEBE, Universitat Politècnica de Catalunya, \\ c/Eduard Maristany 10-14, E-08019 Barcelona, Spain \\ ${ }^{2}$ B. Braun Surgical, S.A., Carretera de Terrassa 121, 08191 Rubí (Barcelona), Spain
}

Received 24 December 2016; accepted in revised form 25 March 2017

\begin{abstract}
Poly( $\varepsilon$-caprolactone) (PCL) films reinforced with polylactide (PLA) microfibers were prepared by two methodologies: a) melt pressing of an electrospun PLA mat between two PCL films, and b) melt pressing of a co-electrospun mat composed of PLA microfibers and PCL nanofibers. Electrospinning conditions were selected for each polymer to obtain films loaded with 10, 20 and $30 \mathrm{wt} \%$ of PLA. Thermal and mechanical properties varied depending on the preparation method. Thus, PLA crystallinity was higher when films were obtained by the co-electrospinning process, as revealed from DSC and synchrotron X-ray diffraction data since cold crystallization of the highly oriented PLA microfibers was favored in the subsequent heating run when they were in close contact with PCL nanofibers. Samples obtained by co-electrospinning also showed higher mechanical properties (e.g. Young modulus) with increasing PLA load. In this case, fracture surfaces showed significant interactions between fibers and the PCL matrix and decreased fiber pull-out.

All fabrics were also loaded with chlorhexidine (CHX) as a hydrophilic bactericide agent. A delayed release was observed when the drug was only loaded into the electrospun PLA microfibers, and diffusion varied with the method of preparation. In all cases, samples had a clear bactericide effect against Gram positive and Gram negative bacteria. Nevertheless, the protective effect was slightly lower when CHX was only loaded in the reinforcing PLA microfibers.
\end{abstract}

Keywords: reinforcements, electrospinning, poly(e-caprolactone), polylactide, bactericide effect

\section{Introduction}

Electrospinning is a technique that allows fibers having diameters from a nanometric to a micrometric scale to be obtained from a wide range of polymeric materials and for multiple applications mainly in the biomedical field when biodegradable and biocompatible polymers are involved [1-11]. In fact, the derived mats can mimic the extracellular matrix, be used with some advantages in tissue regeneration, encapsulate drugs for local and sustained release, and allow surface modification and development of nanosensors [12].

The advantage of this technique is also linked to its great versatility and simplicity. Basically, this electrostatic technique only involves the use of a high voltage field to charge the surface of a polymer solution droplet that is held at the end of a capillary tube, in such a way that a liquid jet is ejected towards a grounded target (collector) placed at a fixed distance. The success of the process mainly depends on solution properties (i.e. polymer concentration, nature of the solvent, conductivity and viscosity of the solution) and operational parameters (i.e. diameter of the needle, applied voltage, tip-collector distance and flow rate) [3, 5-8].

Electrospun micro/nanofibers can also be used as reinforcing materials for biodegradable matrices with low mechanical properties [13-18]. This feature

$\overline{{ }^{*} \text { Corresponding author, e-mail: Jordi.Puiggali@,upc.edu }}$ (C) BME-PT 
appears highly interesting when these weak matrices must be loaded with pharmacological agents since the incorporated drugs usually lead to a significant loss of material properties. Reinforced and drug loaded composites have been prepared by a melt compression technique (method 1) [16], supporting the achieved results the formulated expectations. According to this method, a fibrous mat of the hard reinforcing polymer (e.g. polylactide, PLA) is placed between two sheets of the soft polymer (e.g. poly( $\varepsilon$ caprolactone), PCL) that will constitute the matrix after molding at a temperature higher than its melting point and lower than that of the electrospun fibers (Figure 1).

It has also been proved that the addition of electrospun fibers of nylon 6 and polyvinylpirrolidone improved the physical and mechanical properties and allowed tuning the biodegradation behavior of poly $(\varepsilon-$ caprolactone) $[17,18]$. In addition, nylon electrospun fibers have also been evaluated as appropriate fillers to drastically improve mechanical properties of biodegradable polylactide (i.e. the Young modulus increased up to 3-fold with respect the neat polymer) despite in this case the application is not so clear due to the inherent good properties of the polymer matrix [19]. Similar reinforced laminates based on nondegradable materials have also been studied. It was demonstrated that electrospun fibers can effectively increase the impact properties of composites because of the good load distribution behavior of fibers and the absence of interleaves that could alter the thickness of the composites [20].

An alternative fabric method to obtain matrices reinforced with electrospun fibers consists in the use of a dual electrospinning system (method 2), as depicted in Figure 1. In this case, fibers of each constitutive polymer are deposited in a common rotary collector. These fibers are generated by independent jets ejected from needles facing each other and separated by the collector. In this way, disturbing effects from the two electrically charged jets should be minimized while high fiber mixing efficiency should be expected. The co-electrospun fibrous mat is subsequently molded at an intermediate temperature between those of the melting point of each polymer (i.e. just some degrees above the melting point of PCL). Note that molding is performed with a mat where fibers of each polymer are in close contact and well mixed, which may be advantageous with respect to the above indicated method 1 . The selective fusion of PCL nanofibers should render after cooling, a solid homogeneous laminate where PLA was uniformly dispersed. Reinforcement of polymer matrices by either of the indicated methods requires a sufficient difference in

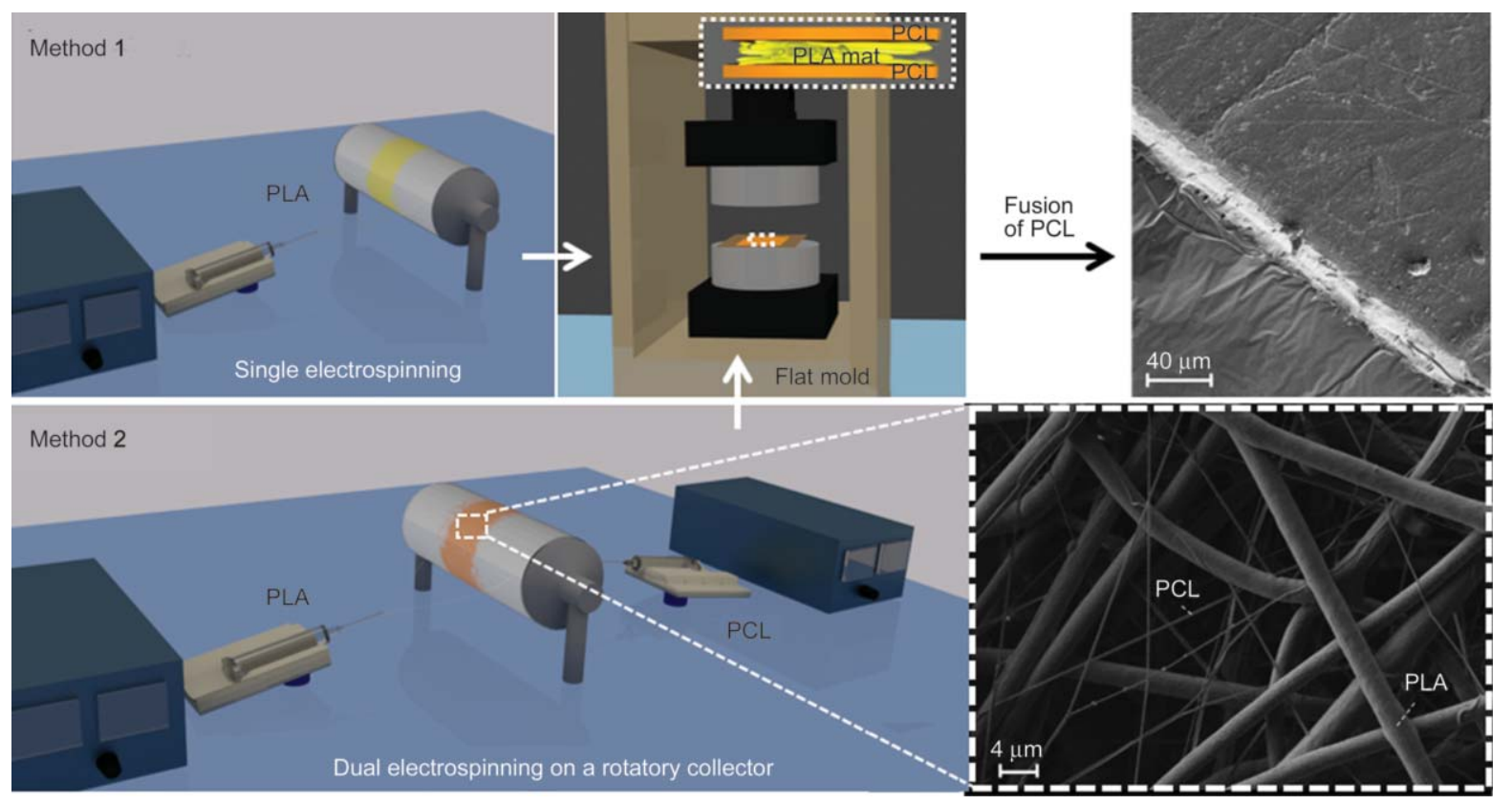

Figure 1. Schematic representation of the two applied procedures to obtain PCL pieces reinforced with PLA microfibers: Molding a PLA electrospun fibrous mat between PCL sheets (method 1), and partial melting of a co-electrospun fibrous mat constituted by PLA and PCL and obtained by using a common rotary collector (method 2). SEM micrographs showing PCL and PLA nanofibers in the co-electrospun mat and the compact molded pieced obtained after the selective melting of PCL are also included in the scheme. 
the melting temperatures of the two selected biodegradable polymers. Therefore, we considered poly ( $\varepsilon$-caprolactone), which has a melting point close to $60^{\circ} \mathrm{C}$, as the polymer matrix and polylactide with a melting point higher than $150^{\circ} \mathrm{C}$ as the reinforcing fiber. Note that this model system is similar from a calorimetric point of view to other combinations that involve polymers widely employed as wound closure materials. Polydioxanone $\left(T_{\mathrm{f}}: 115^{\circ} \mathrm{C}\right)$ - polyglycolide $\left(T_{\mathrm{f}}: 225^{\circ} \mathrm{C}\right)$ or polydioxanone - polyglyconate $\left(T_{\mathrm{f}}: 215^{\circ} \mathrm{C}\right.$ ) are significant examples that open potential applications in the field of sutures by adding reinforcing nanofibers, which should counteract the loss of properties caused by incorporation of pharmacological agents.

The present work is focused on covering the following items: a) preparation of PCL matrices reinforced with drug loaded PLA nanofibers comparing the suitability of the two proposed methodologies, b) characterization of the reinforced samples, including thermal and mechanical properties, and c) study of the drug delivery behavior and the biological effect when a model drug compound is loaded according to the two systems.

Scaffolds having an antibacterial activity are receiving nowadays great attention [21-23], being chlorhexidine (1,1'-hexamethylene-bis-5-(4-chlorophenyl) biguanide, $\mathrm{CHX}$ ) one of the simplest and most employed bactericide agents [24]. In this work, we selected CHX as a model drug, considering also the possibility of achieving a delayed release. By embedding mats constituted by drug loaded microfibers into a biodegradable polymeric matrix. Release from different loaded samples (i.e. drug incorporated into the reinforcing fibers, into the polymer matrix and into both the matrix and the electrospun mat) will be studied. Note that the hydrophilic character of $\mathrm{CHX}$ should lead to a practically immediate release in aqueous media, which is beneficial when a rapid effect is desired, but it may also be interesting to have a drug reservoir to prevent future contaminations. CHX was selected as a drug model with the worst conditions for a delayed release (e.g. high diffusivity due to its low molecular size, high affinity towards aqueous release media and low affinity towards hydrophobic matrices and reinforcements), with the expected effect probably being clearer when high molecular weight hydrophobic drugs were employed.

\section{Experimental section}

\subsection{Materials}

A commercial PLA from Natureworks ${ }^{\circledR}$ with $95.8 \mathrm{wt} \%$ of L-lactic isomer content was used (PLA $2002 \mathrm{D}$ grade). According to the manufacturer, PLA $2002 \mathrm{D}$ is a transparent solid with a density of $1.24 \mathrm{~g} / \mathrm{cc}$. Its calorimetric and mechanical properties are defined by a glass transition temperature $\left(T_{\mathrm{g}}\right)$ of $58^{\circ} \mathrm{C}$, a melting point $\left(T_{\mathrm{m}}\right)$ of $153^{\circ} \mathrm{C}$, a tensile modulus $(E)$ of $3500 \mathrm{MPa}$, a tensile strength $(\sigma)$ of $53-$ $60 \mathrm{MPa}$ and a tensile elongation $(\gamma)$ of $6 \%$. Number and weight average molecular weights and polydispersity index determined by GPC were 98100 , $181000 \mathrm{~g} / \mathrm{mol}$ and 1.85 , respectively [25].

PCL $\left(M_{\mathrm{w}}: 65,000 \mathrm{~g} / \mathrm{mol}\right)$ and chlorhexidine $(\mathrm{CHX})$ were purchased from Sigma-Aldrich (St. Louis, USA). The bacterial strains Escherichia coli CECT 101 and Staphylococcus epidermidis CECT 231 were obtained from the Spanish Type Culture Collection (Valencia, Spain).

\subsection{Measurements}

${ }^{1} \mathrm{H}-\mathrm{NMR}$ (proton nuclear magnetic resonance) spectra were recorded with a Bruker AMX-300 spectrometer operating at $300.1 \mathrm{MHz}$. Chemical shifts were calibrated using tetramethylsilane as the internal standard and $\mathrm{CDCl}_{3} \delta\left({ }^{1} \mathrm{H}\right)=7.26 \mathrm{ppm}$ and deuterated DMSO (dimethyl sulfoxide) $\delta\left({ }^{1} \mathrm{H}\right)=2.50 \mathrm{ppm}$ as solvents.

Calorimetric data were obtained by differential scanning calorimetry with a TA Instruments Q100 series with $T_{\text {zero }}$ technology and equipped with a refrigerated cooling system (RCS). Experiments were conducted under a flow of dry nitrogen with a sample weight of approximately $5 \mathrm{mg}$ and calibration was performed with indium. A four run protocol was employed in all cases to characterize the samples: first, a heating run at $20^{\circ} \mathrm{C} / \mathrm{min}$ up to $190^{\circ} \mathrm{C}$; second, a cooling run at $10^{\circ} \mathrm{C} / \mathrm{min}$ up to $-50^{\circ} \mathrm{C}$ after keeping the sample in the melt state for $5 \mathrm{~min}$ to wipe off its thermal history; third, a second heating run at $20^{\circ} \mathrm{C} / \mathrm{min}$, and finally a third heating run performed at $20^{\circ} \mathrm{C} / \mathrm{min}$ with the sample quenched up to $-50{ }^{\circ} \mathrm{C}$ from the melt state at the maximum cooling rate allowed by the equipment.

Optical micrographs were taken with a Zeiss Axioskop 40 Pol light polarizing microscope equipped with a Zeiss AxiosCam MRC5 digital camera. 
Scanning electron microscopy (SEM) was used to examine the morphology of electrospun fibers and fracture surfaces. Carbon coating was accomplished with a Mitec k950 Sputter Coater (fitted with a film thickness monitor k150x (Quorum Technologies Ltd., West Sussex, UK). SEM micrographs were obtained with a Zeiss Neon 40 EsB instrument (Carl Zeiss, Oberkochen, Germany).

Mechanical properties were determined with a Zwick Z2.5/TN1S (Zwick/Roell; Ulm, Germany) testing machine in stress-strain tests carried out at a deformation rate of $10 \mathrm{~mm} / \mathrm{min}$. The load cell capacity was $100 \mathrm{kN}$. Mechanical parameters were evaluated by means of the testXpert software of Zwick. In the case of the elastic modulus calculation, force values were delimited to the lineal part of the representation. Measurements were performed on rectangular samples $\left(30 \times 5 \times 0.35 \mathrm{~mm}^{3}\right)$ cut from melt-pressed pieces. The mechanical parameters were averaged from a minimum of six measurements for each polymer sample.

Time resolved WAXD (wide angle X-ray diffraction) experiments were conducted at the NCD beamline (BL11) of the Alba synchrotron radiation light facility in Cerdanyola del Vallès (Catalunya). The beam was monochromatized to a wavelength of $0.1 \mathrm{~nm}$. Polymer samples were confined between Kapton films and then held on a Linkam HFSX-350-CAP hot stage with temperature control within $\pm 0.1{ }^{\circ} \mathrm{C}$. WAXD profiles were acquired during heating and cooling runs in time frames of $20 \mathrm{~s}$ and rates of $10^{\circ} \mathrm{C} / \mathrm{min}$. The WAXD detector was calibrated with diffractions of a standard of a $\mathrm{Cr}_{2} \mathrm{O}_{3}$ sample. The diffraction profiles were normalized to the beam intensity and corrected considering the empty sample background.

Unloaded and CHX loaded electrospun fibers were prepared using optimized parameters (i.e. needlecollector distance, voltage and flow rates) and solvent conditions (i.e. solvent ratio, and polymer and drug concentrations). Electrospinning of PLA was performed using an acetone- $\mathrm{CHCl}_{3}(1: 2, \mathrm{v}: \mathrm{v})$ mixture with a polymer concentration of $10 \mathrm{wt} \%$ [16], whereas PCL was electrospun in an EtOH-CHCl $3(1: 2, \mathrm{v}: \mathrm{v})$ mixture and at a concentration of $22 \mathrm{wt} \%$. The CHX content of the electrospinning solutions was adjusted to obtain PLA and/or PCL electrospun fibers loaded with $0.5 \mathrm{wt} \%$ of the drug. The insolubility of $\mathrm{CHX}$ in the acetone- $\mathrm{CHCl}_{3}(1: 2, \mathrm{v}: \mathrm{v})$ mixture [26] required the use a ternary mixture for the electrospinning of
CHX loaded PLA by adding a $10 \mathrm{v} \%$ of dimethyl sulfoxide where CHX was initially dissolved. All electrospinning experiments were carried out at room temperature.

A dual electrospinning system was used to prepare scaffolds constituted by a mixture of PCL and PLA microfibers, as depicted in Figure 1. Electrospun fibers were collected on a grounded rotary collector operating at $30 \mathrm{rpm}$ and at a variable distance (6$8 \mathrm{~cm}$ ) from two equidistant needle tips (inside diameter of $0.84 \mathrm{~mm}$ ) at room temperature. The needles were placed facing each other in order to minimize disturbing effects between the two electrically charged jets of PLA and PCL solutions. The voltage was $15 \mathrm{kV}$ for PLA and varied between 23 and $30 \mathrm{kV}$ for PCL. Two high-voltage suppliers (Gamma High Voltage Research, ES30-5W) were used. Polymer solutions were delivered via two KDS100 infusion syringe pumps (KD Scientific, USA) to control the flow rate (from 3.7 to 10.0 for PLA and from 10.5 to $15 \mathrm{~mL} \cdot \mathrm{h}^{-1}$ for PCL). Flow rates for each polymer solution were adjusted to obtain the desired polymer composition in the final fibrous matrix.

\subsection{Preparation of reinforced PCL films by single electrospinning of PLA (method 1)}

Mats of unloaded and CHX loaded PLA electrospun microfibers were prepared as above indicated using a single syringe. PCL films were obtained by pressing $350 \mathrm{mg}$ of the polymer (25 Ton Ring Press, Research \& Industrial Instruments Company, London, UK) in a flat mold of $4 \mathrm{~cm} \times 6 \mathrm{~cm}$ internal dimensions, which was covered with Teflon ${ }^{\circledR}$ sheets to avoid polymer adhesion to the mold. Samples were heated at $75^{\circ} \mathrm{C}$ (i.e. $15^{\circ} \mathrm{C}$ above the melting point of PCL) for 12 min using heating plates and a temperature controller (Graseby Specac, Kent, England). In order to obtain the reinforced matrices, electrospun PLA mats were cut into rectangular pieces $(4 \mathrm{~cm} \times 6 \mathrm{~cm})$ and placed between two molded PCL films. Final PLA concentrations of 10,20 and $30 \mathrm{wt} \%$, were obtained by adding PLA mats until reaching weights close to 78,175 or $300 \mathrm{mg}$. After melt pressing as above indicated, reinforced films with thicknesses between 250 and $310 \mu \mathrm{m}$ were obtained. Samples will be denoted as PLA/PCL- $x$, where $x$ is the theoretical weight percentage of PLA. PCL films prepared by solvent casting were used when $\mathrm{CHX}$ was also incorporated into PCL. In this case, the same solvent selected for electrospinning of PCL was used. 


\subsection{Preparation of reinforced PCL films by dual electrospinning of PLA and PCL (method 2)}

Reinforced PCL films were prepared by pressing several rectangular sections $(4 \mathrm{~cm} \times 6 \mathrm{~cm})$ of the appropriate co-electrospun mat until obtaining a total weight of $400 \mathrm{mg}$. These mats were placed into the flat mold of the same internal dimensions which was covered with Teflon ${ }^{\circledR}$ sheets. Samples were heated at $75^{\circ} \mathrm{C}$ for $12 \mathrm{~min}$ as indicated in the previous subsection. Pressure was progressively increased from 1 to 4 bar. Polymer films with a thickness close to $150 \mu \mathrm{m}$ were recovered after cooling the mold to room temperature. Samples will be denoted by indicating the co-electrospinning experimental procedure (i.e. $\mathrm{C}$ for co-electrospinning) and the polylactide $w t \%$ (i.e. C-PLA/PCL-30, C-PLA/PCL-20 and C-PLA/PCL-10 correspond to blends with 30, 20 and $10 \mathrm{wt} \%$ of PLA, respectively).

\subsection{Drug release}

Drug release experiments were performed in triplicate with square pieces prepared by both methodologies (total weight 10-25 mg). Samples were introduced in Falcon tubes with $40 \mathrm{~mL}$ of Sorensen's buffer ( $\mathrm{pH}$ 7.4) and a mixture of Sorensen's medium with ethanol $70 \%(\mathrm{v} / \mathrm{v})$. The released drug concentration was determined with a UV-3600 spectrometer (Shimadzu, Japan) by absorbance measurements at a wavelength of $260 \mathrm{~nm}$, which corresponds to the maximum of the absorbance profile. Calibration curves were prepared using different stock solutions of the assayed CHX drug in the two different release media and relating the measured absorbance at $260 \mathrm{~nm}$ to the concentration. $1 \mathrm{~mL}$ of sample was taken from each tube at predetermined times and replaced with fresh medium. The presented results are an average value of the replicates.

Encapsulation efficiency was calculated by measuring the amount of drug incorporated into the scaffold by UV-vis absorbance measurements at a wavelength of $260 \mathrm{~nm}$. When the release finished, the loaded sample was dissolved in chloroform. CHX was separated by centrifugation after the precipitation of polymers by addition of ethanol (final concentration chloroform - ethanol mixture: 5:95 v:v).

\subsection{Antimicrobial test assays}

Antimicrobial tests were performed to determine the bacteriostatic effect of the loaded drug. Thus, adhesion and growth assays of both Escherichia coli (E. coli) and Staphylococcus epidermidis (S. epidermidis) were performed on the PCL reinforced films using 24-well culture plates. Bacterial inhibition was quantitatively and qualitatively evaluated. In the first case, $0.05 \mathrm{~mL}$ of sample was taken every two hours for $8 \mathrm{~h}$ and final samples after 24 and $48 \mathrm{~h}$. Absorbance was measured in a microplate reader at $650 \mathrm{~nm}$ to determine bacterial growth. Regarding the qualitative method, around $5 \mathrm{mg}$ of loaded and unloaded samples was placed into Agar diffusion plates and seeded with $10^{4} \mathrm{UFC} / \mathrm{mL}$ of both bacteria separately. The culture medium was prepared with $10.6 \mathrm{~g}$ of Brilliant Green Agar (BGA, Scharlau), dissolved in $200 \mathrm{~mL}$ of Milli-Q water and sterilized in an autoclave at $121^{\circ} \mathrm{C}$ for $30 \mathrm{~min}$. Plates were filled with $15 \mathrm{~mL}$ of medium and kept at rest at room temperature to allow solidification of the medium. Inhibition halo images were taken after incubation of samples with bacteria at $37^{\circ} \mathrm{C}$ for $24 \mathrm{~h}$.

For bacterial adhesion tests, the culture medium was aspirated after the proliferation measurements and the material was washed three times with distilled water. Then, $0.5 \mathrm{~mL}$ of sterile $0.01 \mathrm{M}$ sodium thiosulfate was added to each well to detach bacteria adhered on the surface of the sample. Plates were then shaken at $100 \mathrm{rpm}$ for $1 \mathrm{~h}$. Finally, the polymeric samples were removed and $500 \mu \mathrm{L}$ of culture medium was added to the wells and incubated at $37^{\circ} \mathrm{C}$ and $100 \mathrm{rpm}$ for $24 \mathrm{~h}$. Absorbance was measured in a microplate reader at $650 \mathrm{~nm}$ when culture medium was added and also after $24 \mathrm{~h}$. Each sample was analyzed in quadruplicate and the results averaged. To determine variance and significant difference of the samples, a oneway ANOVA test and a $t$-test with a $95 \%(p<0.05)$ confidence level were performed.

\section{Results and discussion}

\subsection{Reinforced PCL films derived from dual electrospinning of PLA and PCL micro/nanofibers}

The electrospinning conditions selected to obtain PLA microfibers and PCL nanofibers are summarized in Table 1. Basically, processing parameters for PLA were based on those previously optimized for preparing fibers in the micrometric range [16]. Selection of PCL conditions was not so restrictive since resulting fibers were melted in the subsequent step. Therefore, parameters were chosen to get PCL fibers with diameters in the nanometric scale, which appears an ideal size to facilitate the subsequent melting 
Table 1. Selected parameters for PLA and PCL to get co-electrospun mats of the indicated compositions. Diameter of fibers are also indicated.

\begin{tabular}{|c|c|c|c|c|c|c|c|c|}
\hline \multirow{2}{*}{$\begin{array}{c}\text { PLA:PCL } \\
{[\mathbf{w t : w t}]}\end{array}$} & $\begin{array}{c}\text { Flow } \\
{\left[\mathbf{m L} \cdot \mathbf{h}^{-\mathbf{1}}\right]}\end{array}$ & $\begin{array}{c}\text { Distance } \\
{[\mathbf{c m}]}\end{array}$ & $\begin{array}{c}\text { Voltage } \\
{[\mathbf{k V}]}\end{array}$ & $\begin{array}{c}\text { Diameter } \\
{[\boldsymbol{\mu \mathbf { m } ]}]}\end{array}$ & $\begin{array}{c}\text { Flow } \\
{\left[\mathbf{m L} \cdot \mathbf{h}^{-\mathbf{1}}\right]}\end{array}$ & $\begin{array}{c}\text { Distance } \\
{[\mathbf{c m}]}\end{array}$ & $\begin{array}{c}\text { Voltage } \\
{[\mathbf{k V}]}\end{array}$ & $\begin{array}{c}\text { Diameter } \\
{[\mathbf{n m}]}\end{array}$ \\
\hline $10: 90$ & 3.7 & 6 & 15 & $1.8 \pm 0.2$ & 15.0 & 8 & 23 & $175 \pm 35$ \\
\hline $20: 80$ & 6.7 & 7 & 15 & $1.4 \pm 0.2$ & 12.0 & 8 & 30 & $235 \pm 30$ \\
\hline $30: 70$ & 10.0 & 7 & 15 & $1.4 \pm 0.2$ & 10.5 & 8 & 30 & $220 \pm 30$ \\
\hline
\end{tabular}

process. Specifically, a higher voltage $(23-30 \mathrm{kV})$ than that used for PLA was selected. In addition, the solvent mixture was modified and ethanol was employed instead of acetone. These conditions allowed thinner fibers to be obtained since they were subjected to a higher stress. In addition, it should be considered that differences in the viscosity and conductivity of the solution could influence on the morphology giving rise to PCL fibers with smaller diameters. Note also that flow rates for PLA and PCL solutions had to be changed in order to obtain the desired mat composition (i.e. PLA [wt \%] of 10, 20 and 30\%). Obviously, flow rates increased and decreased for PLA and PCL, respectively, as the PLA [wt $\%$ ] of the

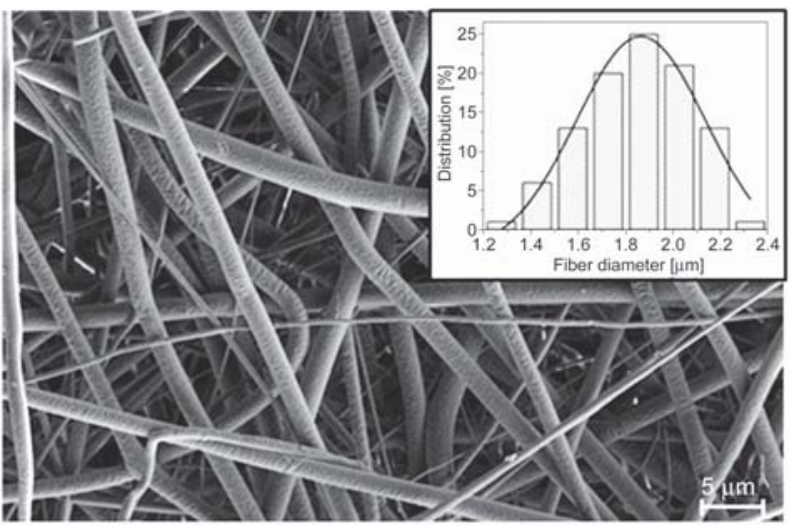

a)

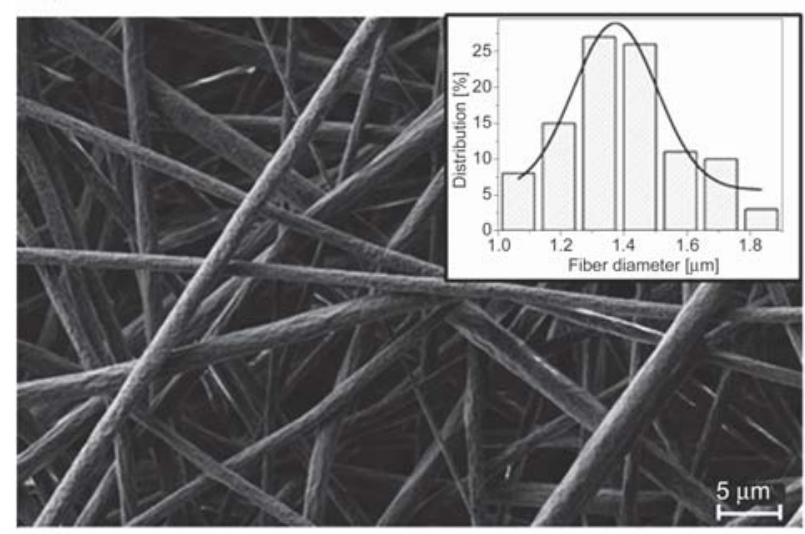

c) final mat was increased. Homogeneous and continuous PLA and PCL fibers were attained under all selected conditions, as shown in Figure 2 for some representative samples. The diameter sizes always had a monomodal distribution (insets of Figure 2) (average diameters are also summarized in Table 1). The most striking feature for PLA and PCL fibers is that the average diameter tends to increase when the flow rate decreases. Nevertheless, it should be pointed out that the voltage was increased for electrospinning of PCL when the flow rate decreased, which should lead to a compensatory effect since a larger pendant drop was formed and a higher diameter was favored. In the case of PCL, the tip-collector distance was

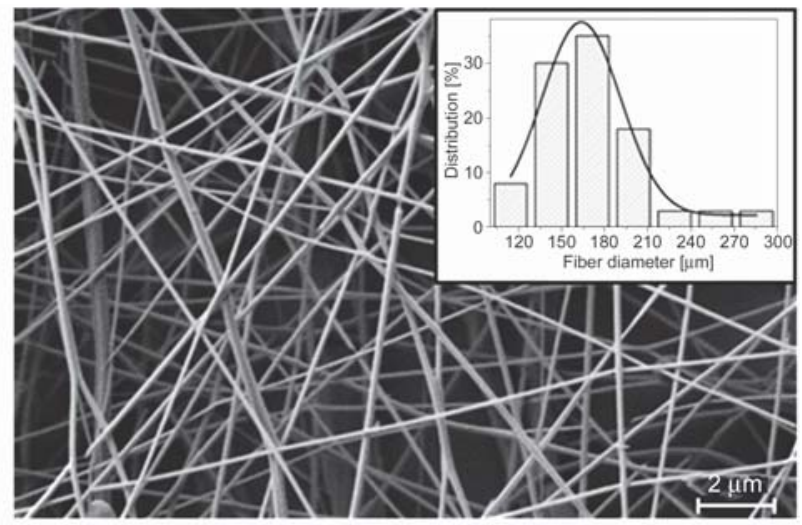

b)

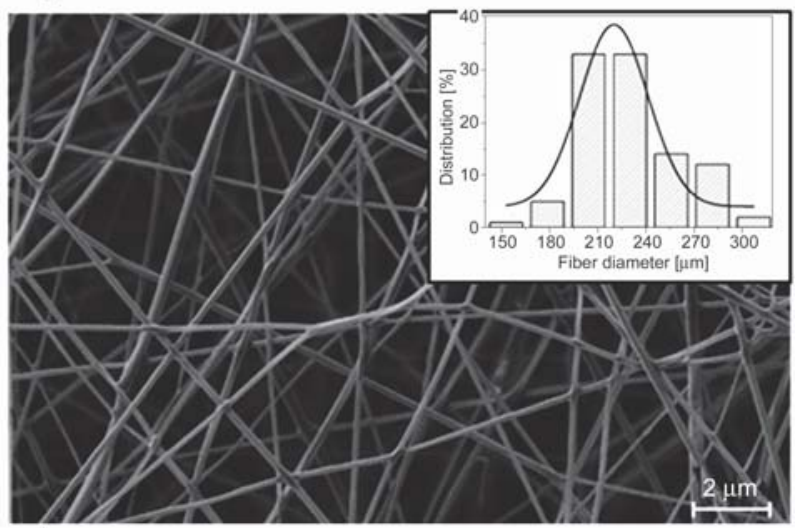

d)

Figure 2. SEM micrographs showing PLA (a, c) and PCL (b, d) electrospun fibers prepared by single-jet electrospinning under the conditions previously selected to obtain co-electrospun fibrous mats with PLA wt $\%$ of $10 \%(a, b)$, and $30 \%$ (c, d). Diameter distribution curves of corresponding PLA and PCL electrospun fibers are also indicated. 
kept constant, whereas for PLA it was slightly increased when the flow rate increased, with a slight decrease in the diameter being also observed. On the other hand, some authors have reported that above a limiting value of the flow rate, the fiber diameter tends to decrease [27].

Texture of PCL and PLA electrospun fibers could also be clearly differentiated. Thus, a smooth surface was characteristic of thin PCL fibers, whereas the presence of longitudinal striations and more frequently a porous surface were characteristic of PLA microfibers. Figure 3 shows representative SEM micrographs of coelectrospun mats with the 10 and $20 \mathrm{wt} \%$ compositions. They revealed the difference in ratio between PLA and PCL fibers and a well-mixed distribution.

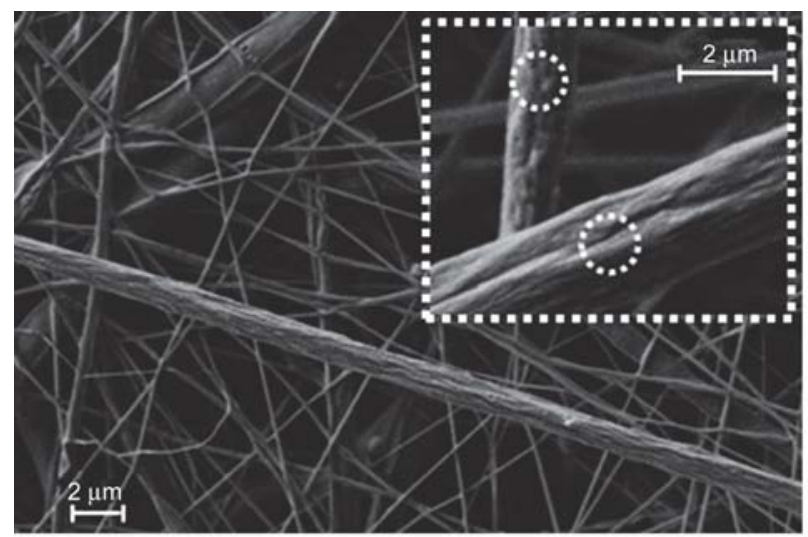

a)
Note that both kinds of fibers can be easily distinguished because of their different diameter size and texture. The insets of Figure 3 clearly show the presence of striations and pores in the PLA microfibers. A representative ${ }^{1} \mathrm{H}-\mathrm{NMR}$ spectrum of a co-electrospun mat is shown in Figure 4. The area of the typical quadruplet associated with the $\mathrm{CH}$ group of PLA $(5.22-5.10 \mathrm{ppm})$ and the area of the triplet associated with the $\mathrm{CH}_{2}-\mathrm{O}$ group of PCL (4.15-4.00 ppm) were used to estimate the composition of the scaffold according to Equation (1):

$$
\begin{aligned}
& \text { PLA }[w t \%]= \\
& \qquad \frac{A_{5.22-5.10} \cdot 72.1}{\left(A_{5.22-5.10} \cdot 72.1+0,5 \cdot A_{4.15-4.00} \cdot 114.1\right)}
\end{aligned}
$$

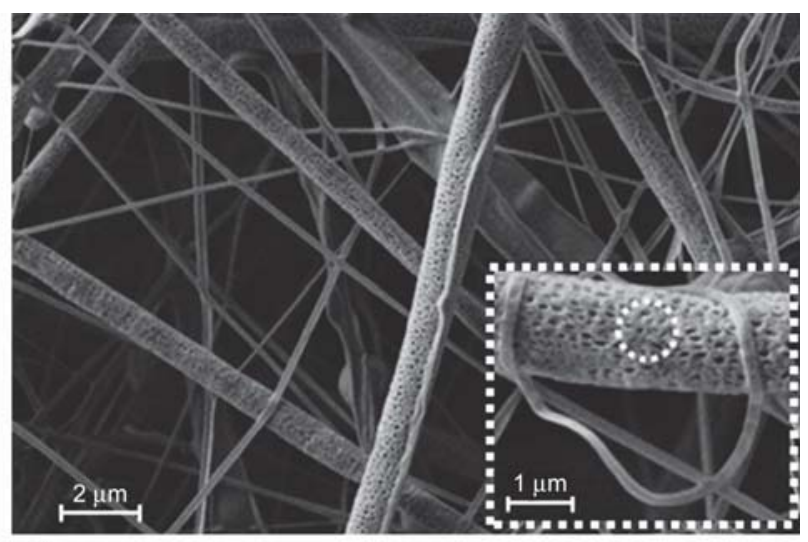

b)

Figure 3. SEM micrographs showing the fibrous mats of co-electrospun samples containing PLA theoretical weight percentages of $10 \%$ (a) and $20 \%$ (b). Details of the surface textures are shown in the corresponding high magnification insets.

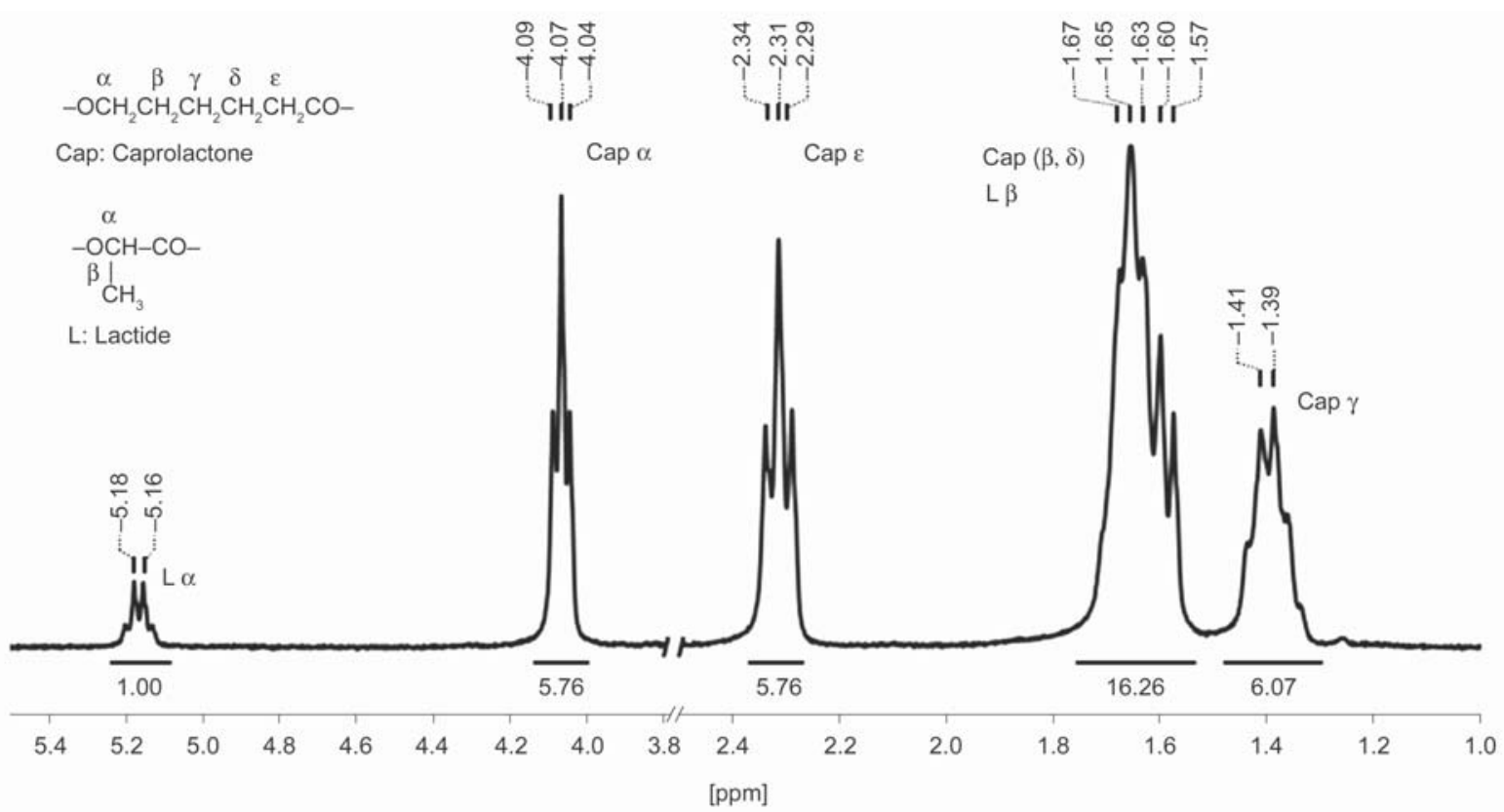

Figure 4. ${ }^{1} \mathrm{H}-\mathrm{NMR}$ spectra of the PLA/PCL co-electrospun sample containing $30 \mathrm{wt} \%$ of PLA. Assignment of signals, as well as the areas of main peaks, is indicated. 
Table 2. Theoretical and experimental compositions of reinforced samples prepared by co-electrospinning and single electrospinning

\begin{tabular}{|c|c|c|}
\hline \multirow{2}{*}{ Samples } & $\begin{array}{c}\text { Theoretical } \\
\text { composition } \\
\text { PLA:PCL } \\
\text { [wt:wt] }\end{array}$ & $\begin{array}{c}\text { Experimental } \\
\text { composition PLA:PCL } \\
\text { [wt:wt] }\end{array}$ \\
\hline \multirow{2}{*}{$\begin{array}{l}\text { Reinforced films by } \\
\text { co-electrospinning }\end{array}$} & $10: 90$ & $8.7( \pm 1.9): 91.3( \pm 1.9)$ \\
\cline { 2 - 3 } & $20: 80$ & $18.4( \pm 2.9): 81.6( \pm 2.8)$ \\
\cline { 2 - 3 } & $30: 70$ & $29.8( \pm 3.8): 70.2( \pm 3.8)$ \\
\hline \multirow{2}{*}{$\begin{array}{l}\text { Reinforced films by } \\
\text { single electrospinning }\end{array}$} & $10: 90$ & $11.3( \pm 1.8): 88.7( \pm 1.8)$ \\
\cline { 2 - 3 } & $20: 80$ & $19.8( \pm 3.7): 80.2( \pm 3.7)$ \\
\cline { 2 - 3 } & $30: 70$ & $29.4( \pm 4.7): 70.6( \pm 4.7)$ \\
\hline
\end{tabular}

where 72.1 and 114.1 are the molecular weights of lactide and $\varepsilon$-caprolactone units, respectively.

Table 2 compares the theoretical composition of electrospun mats and the experimental values that correspond to an average of seven samples taken at regular intervals along the diagonal of the rectangular mat. In all cases, a relatively good agreement was observed, demonstrating that flow rates were properly chosen and that a homogeneous distribution was achieved by dual electrospinning and the use of a rotary collector.

\subsection{Reinforced PCL films derived from single electrospinning of PLA}

PLA was electrospun using the same parameters selected for the dual electrospinning process (Table 1). Namely, they were varied according to the final composition since it was preferable to use PLA microfibers completely comparable (in size and morphology) with those attained by co-electrospinning. ${ }^{1} \mathrm{H}-\mathrm{NMR}$ spectra were employed as above indicated to determine the composition of molded samples. Again, a good agreement was observed between theoretical and experimental values (Table 2), which means that there was a negligible loss of the lower viscosity PCL sample through the mold walls.

\subsection{Thermal properties of PCL films reinforced with PLA}

Calorimetric data of samples differing in composition and preparation methodology are summarized in Table 3. These data correspond to the four run protocol shown in Figure 5 for a representative reinforced sample that allows thermal behavior in terms of fusion and crystallization to be determined from the

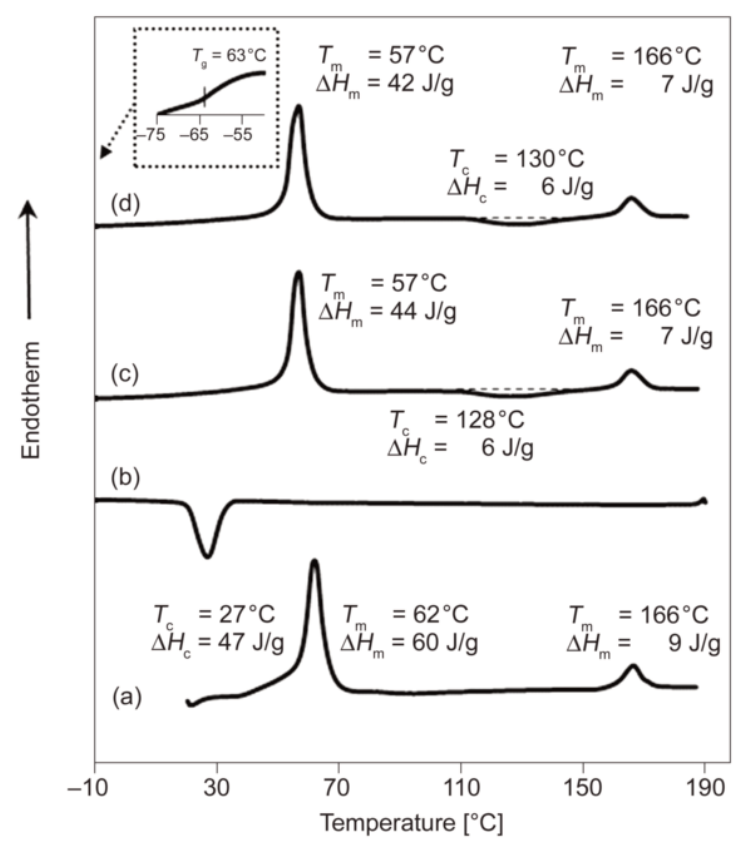

Figure 5. DSC scans performed with the reinforced sample prepared by molding a co-electrospun mat containing $30 \mathrm{wt} \%$ of PLA: a) first heating run; b) cooling run after keeping the sample at $190^{\circ} \mathrm{C}$ for $5 \mathrm{~min}$; c) second heating run performed with the above cooled sample, and d) third heating run performed with a sample cooled at the maximum rate allowed by the equipment from 190 to $-50^{\circ} \mathrm{C}$.

Table 3. Calorimetric data of reinforced samples with different composition and processed according to the two proposed methodologies

\begin{tabular}{|c|c|c|c|c|c|c|c|c|c|c|c|c|c|c|c|c|c|c|}
\hline \multirow{3}{*}{ Sample } & \multicolumn{4}{|c|}{$1^{\text {st }}$ heating } & \multirow{2}{*}{\multicolumn{2}{|c|}{$\begin{array}{c}\text { Cooling } \\
\text { PCL }\end{array}$}} & \multicolumn{6}{|c|}{$2^{\text {nd }}$ heating } & \multicolumn{6}{|c|}{$3^{\text {rd }}$ heating } \\
\hline & \multicolumn{2}{|c|}{ PCL } & \multicolumn{2}{|c|}{ PLA } & & & \multicolumn{2}{|c|}{ PCL } & \multicolumn{4}{|c|}{ PLA } & \multicolumn{2}{|c|}{ PCL } & \multicolumn{4}{|c|}{ PLA } \\
\hline & $\begin{array}{c}T_{\mathrm{f}} \\
{\left[{ }^{\circ} \mathbf{C}\right]}\end{array}$ & $\begin{array}{l}\Delta H_{\mathrm{f}} \\
{[\mathrm{J} / \mathrm{g}]}\end{array}$ & $\begin{array}{c}T_{\mathrm{f}} \\
{\left[{ }^{\circ} \mathrm{C}\right]}\end{array}$ & $\begin{array}{r}\Delta H_{\mathbf{f}} \\
{[\mathbf{J} / \mathbf{g}]}\end{array}$ & $\begin{array}{c}T_{\mathrm{c}} \\
{\left[{ }^{\circ} \mathbf{C}\right]}\end{array}$ & $\begin{array}{r}\Delta H_{\mathrm{f}} \\
{[\mathrm{J} / \mathrm{g}]}\end{array}$ & $\begin{array}{c}\boldsymbol{T}_{\mathrm{f}} \\
{\left[{ }^{\circ} \mathbf{C}\right]}\end{array}$ & $\begin{array}{c}\Delta H_{\mathrm{f}} \\
{[\mathrm{J} / \mathrm{g}]}\end{array}$ & $\begin{array}{c}T_{\mathrm{f}} \\
{\left[{ }^{\circ} \mathbf{C}\right]}\end{array}$ & $\begin{array}{c}\Delta H_{\mathrm{f}} \\
{[\mathrm{J} / \mathrm{g}]}\end{array}$ & $\begin{array}{c}T_{\mathrm{c}} \\
{\left[{ }^{\circ} \mathbf{C}\right]}\end{array}$ & $\begin{array}{c}\Delta H_{\mathrm{f}} \\
{[\mathrm{J} / \mathrm{g}]}\end{array}$ & $\begin{array}{c}T_{\mathrm{f}} \\
{\left[{ }^{\circ} \mathbf{C}\right]}\end{array}$ & $\begin{array}{r}\Delta H_{\mathrm{f}} \\
{[\mathbf{J} / \mathbf{g}]}\end{array}$ & $\begin{array}{c}T_{\mathrm{f}} \\
{\left[{ }^{\circ} \mathrm{C}\right]}\end{array}$ & $\begin{array}{l}\Delta \boldsymbol{H}_{\mathrm{f}} \\
{[\mathrm{J} / \mathrm{g}]}\end{array}$ & $\begin{array}{c}T_{\mathbf{c}} \\
{\left[{ }^{\circ} \mathbf{C}\right]}\end{array}$ & $\begin{array}{r}\Delta H_{\mathrm{f}} \\
{[\mathrm{J} / \mathrm{g}]}\end{array}$ \\
\hline $\mathrm{A}$ & 9.8 & \begin{tabular}{|l|l|}
79.1 \\
\end{tabular} & 165.7 & 1.10 & 26.4 & 67.0 & 56.0 & 68.1 & _ & - & - & - & 56.7 & 66.1 & - & - & - & - \\
\hline LA & 6.2 & 72.9 & 164.7 & 0.80 & 27.8 & 63.6 & 57.2 & 62.0 & - & - & 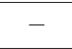 & - & 57.2 & 60.8 & - & - & - & - \\
\hline 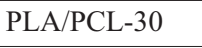 & 9.8 & 64.8 & 165.3 & 2.39 & 30.9 & 56.6 & 56.0 & 55.6 & 64. & 1.2 & - & - & 55.4 & 57.4 & 164.4 & 1.6 & - & - \\
\hline C-PL & 1.6 & 75.3 & 166.4 & 4.50 & 28.9 & 58.6 & 56.1 & 59.8 & 165.2 & 5.6 & 133.3 & 3.8 & 55.5 & 57.4 & 164.9 & 4.7 & 135.0 & 4.7 \\
\hline 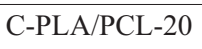 & .8 & 9 & 165.6 & 0 & 8.4 & 51.8 & 56.5 & 52.0 & 165.6 & 3.7 & 131.0 & 2.9 & 56.6 & 51.5 & 165.4 & .1 & 133.7 & 2.8 \\
\hline L-30 & 2.0 & 9.7 & 66.4 & 8.70 & 27.0 & 46.8 & 56.9 & 43.5 & 165.8 & 7.4 & 128.2 & 6.1 & 56.9 & 42.1 & 165.9 & 7.0 & 129.9 & 5.9 \\
\hline
\end{tabular}


melt and glassy state. The following observations can be made:

a) A clear melting peak associated with the PCL matrix can always be detected in the $55-62^{\circ} \mathrm{C}$ temperature interval in DSC traces of the asprocessed samples. The enthalpy is close to $83-86$ and 87-92 J/g (referred to the weight of PCL) for samples prepared by dual and single electrospinning, respectively. These values correspond to high crystallinities that are close to 60 and $63 \%$ when a value of $142 \mathrm{~J} / \mathrm{g}$ for a $100 \%$ crystalline sample is considered [28]. Differences are not highly significant but suggest a better distribution of PLA fibers within the molten PCL phase that slightly hindered the crystallization process in films prepared by co-electrospinning.

b) Interestingly, melting enthalpy and crystallinity associated with PCL clearly decreased in the second and third heating runs (i.e. up to $43-55 \%$, with the lower values being determined for samples prepared by co-electrospinning). Note that these values correspond to samples crystallized in a different way since in this case PCL was completely melted, whereas PLA fibers where always present in the crystallization of molded samples.

c) All reinforced samples showed a small peak between 165 and $167^{\circ} \mathrm{C}$ associated with the fusion of PLA fibers. It is clear that the electrospinning process favored the alignment of PLA chains, giving rise to a significant crystallization process during molding of samples prepared by co-electrospinning. Thus, crystallinities between 29 and $45 \%$ could be estimated considering a melting enthalpy of $93.1 \mathrm{~J} / \mathrm{g}$ for a $100 \%$ crystalline PLA sample [29]. Good contact between PCL and PLA, together with an enhanced cold crystallization process during the heating performed in the mold, was observed. On the contrary, cold crystallization was less favored when samples were prepared by intercalation of PLA mats between PCL films. In this case, crystallinities of PLA were in the $8-11 \%$ range.

d) Cooling runs only showed the crystallization peak of PCL, with PLA remaining in the amorphous state. Note that PLA crystallizes with difficulty from the melt state because chains are not aligned, as is typical in an electrospinning process.

e) Cold crystallization peaks of PLA were observed during the second and third heating runs of samples prepared by dual electrospinning but not for those prepared by single electrospinning. It seems that during the heating scan the better distribution of PLA within the molten PCL phase facilitated its crystallization.

Glass transition of PCL was detected at around $-63^{\circ} \mathrm{C}$ for all quenched samples, but that corresponding to PLA could not be observed because of the overlapping with the PCL melting peak.

\subsection{Structure and morphology of PCL films reinforced with PLA}

X-ray diffraction patterns of reinforced films derived from dual electrospinning exhibited the characteristic reflections of PCL, as shown in Figure 6 for samples enriched with PLA. Thus, four Bragg peaks at $0.415,0.404,0.375$ and $0.367 \mathrm{~nm}$, which corresponded to the (110), (111), (200) and (201) reflections of PCL $[30,31]$, were clearly observed. In addition, the films enriched on PLA (Figure 6 curve a) showed reflections at 0.542 and $0.472 \mathrm{~nm}$, which correspond to the $(200)+(110)$ and (203) reflections of the $\alpha$ form of polylactide $[32,33]$. It is interesting to note that PLA reflections could not be detected in the coelectrospun scaffold (Figure 6 curve b), indicating that PLA crystallized during the molding process, as postulated in the previous section. In fact, time resolved diffraction profiles taken during the heating process (Figure 7) of co-electrospun scaffolds demonstrated that cold crystallization of PLA took place once the PCL nanofibers were completely melted.

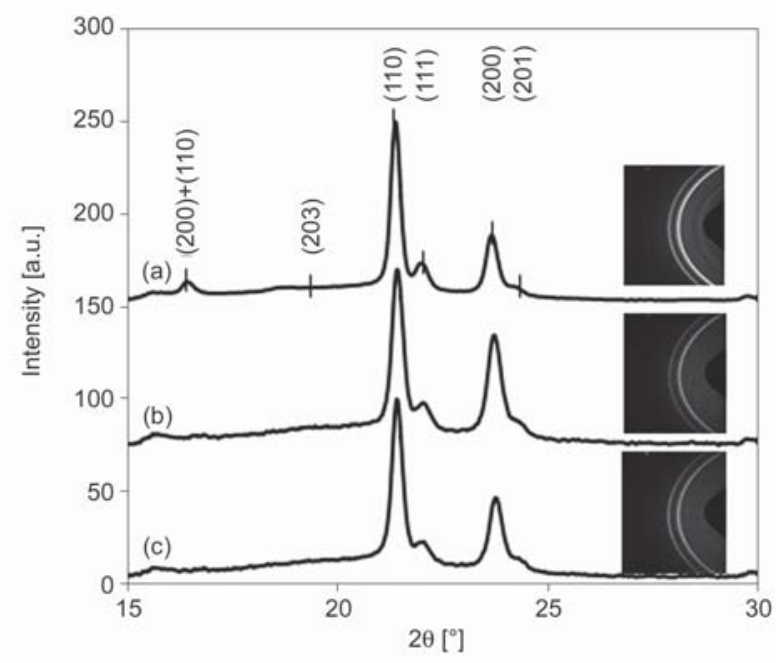

Figure 6. WAXD profiles and corresponding 2D-patterns (insets) obtained from final C-PLA/PCL-30 reinforced films (a), C-PLA/PCL-30 fibrous mat before performing the molding process (b) and PLA/ PCL-30 reinforced films (c). Spacings of main reflections are indicated in nanometers. 


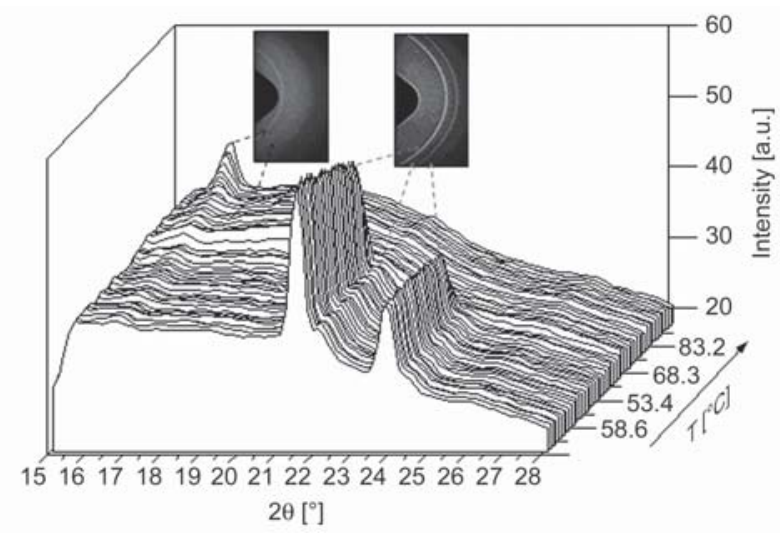

Figure 7. Three-dimensional WAXD profiles taken during a heating scan $\left(10^{\circ} \mathrm{C} / \mathrm{min}\right)$ of a fibrous mat constituted by $30 \mathrm{wt} \%$ of PLA microfibers and $70 \mathrm{wt} \%$ of PCL nanofibers.

PLA reflections were absent in the diffraction patterns of reinforced films prepared by single electrospinning of PLA (Figure 6 curve c). Thus, cold crystallization was not significant during molding when fibers were directly deposited between the two PCL films.

Figure 8 shows polarizing optical micrographs of coelectrospun scaffolds taken at different temperatures. At the high molding temperature, PLA microfibers appear unaltered inside the amorphous background corresponding to PCL. This polymer began to crystallize at temperatures close to $50^{\circ} \mathrm{C}$ and gave rise to well-developed PCL fibrillar spherulites with a typical negative birefringence at room temperature. Micrographs of thin films reveal an average spherulite diameter close $40-50 \mu \mathrm{m}$, with PLA microfibers being randomly dispersed and integrated inside the crystallized spherulites. Microfibers showed a slight birefringence, which indicates a certain degree of orientation of PLA chains.
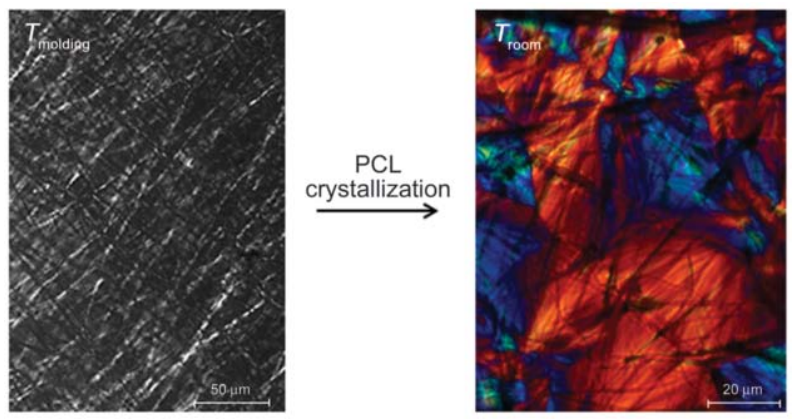

Figure 8. Polarizing optical micrographs showing PLA microfibers embedded in a melted PCL sample, and spherulitic morphologies obtained after cooling to room temperature.

\subsection{Mechanical properties of PCL films reinforced with PLA}

Several works have addressed the reinforcing effect of electrospun fibers [13-20,34], which may be higher than that of conventional fillers due to their high surface contact area with the polymeric matrix. Moreover, the porous PLA scaffold may favor the attainment of an interpenetrating structure, a feature that is logically enhanced by the co-electrospinning set up. The use of microfibers is also justified by recent works indicating that nanofibers clearly reduced the porosity of the scaffold and hindered the achievement of optimal interactions with the melted polyester after performing the molding process [16].

Figures 9 compare stress-strain curves for representative samples and the evolution of the Young modulus with the percentage of incorporated PLA fibers. Table 4 summarizes the increase of elastic modulus and maximum stress with incorporation of PLA microfibers in the PCL matrix as an evidence of an interlocking mechanism $[14,34]$. Experimental data demonstrated that the method employed to reinforce the PCL films had a significant influence on the mechanical behavior. Specifically, a higher increase of the modulus was detected for samples prepared by co-electrospinning because of better interlocking with the PCL matrix. Data also indicated that the presence of electrospun fibers leads to a decrease in

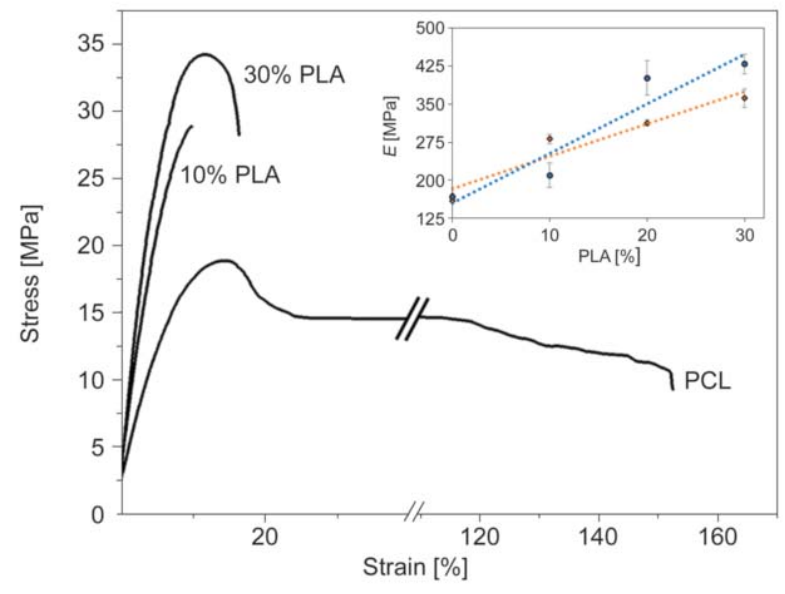

Figure 9. Stress-strain curves of PCL and samples prepared by co-electrospinning and containing 10 and $30 \mathrm{wt} \%$ of PLA. Inset shows the evolution of Young modulus with PLA microfiber content according to the two preparation methods: co-electrospinning (blue circles) and molding an electrospun PLA fibrous mat between PCL films (orange rhombus). 
Table 4. Mechanical properties of PCL films with and without reinforcing PLA fibers

\begin{tabular}{|l|c|c|c|}
\hline \multicolumn{1}{|c|}{ Sample } & $\begin{array}{c}\boldsymbol{E} \\
{[\mathbf{M P a}]}\end{array}$ & $\begin{array}{c}\text { Maximum stress } \\
{[\mathbf{M P a}]}\end{array}$ & $\begin{array}{c}\text { Strain }^{\mathbf{a}} \\
{[\mathbf{\%}]}\end{array}$ \\
\hline PCL film & $159( \pm 7)$ & $15( \pm 3)$ & $150( \pm 14)$ \\
\hline PLA/PCL-10 & $251( \pm 9)$ & $21( \pm 1)$ & $19( \pm 3)$ \\
\hline PLA/PCL-20 & $313( \pm 6)$ & $23( \pm 1)$ & $20( \pm 6)$ \\
\hline PLA/PCL-20 CHX & $262( \pm 6)$ & $19( \pm 4)$ & $20( \pm 4)$ \\
\hline PLA/PCL-30 & $361( \pm 8)$ & $24( \pm 3)$ & $32( \pm 7)$ \\
\hline C-PLA/PCL-10 & $278( \pm 14)$ & $18( \pm 3)$ & $13( \pm 6)$ \\
\hline C-PLA/PCL-20 & $401( \pm 12)$ & $20( \pm 2)$ & $14( \pm 5)$ \\
\hline C-PLA/PCL-20 CHX & $390( \pm 14)$ & $19( \pm 4)$ & $12( \pm 3)$ \\
\hline C-PLA/PCL-30 & $428( \pm 9)$ & $26( \pm 6)$ & $18( \pm 3)$ \\
\hline
\end{tabular}

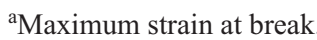

bSamples with CHX loaded into PLA microfibers.

tensile deformation (i.e. maximum strain at break) compared to that of the bulk PCL matrix $[34,35]$. This feature shows clear evidence that most of the stress is supported by PLA, which is rigid and brittle. A not optimal adhesion and interplay between PCL and PLA can be deduced, opening a possibility for further investigations on this topic (e.g. use of compatibilizers, surface grafting, etc.).

Figure 10 illustrates the fracture surface of samples prepared by the two different methodologies. In general, PLA fibers appear always aligned after breaking in contrast with their random orientation in the initial scaffold. Slight differences in terms of matrix deformation and fiber pull-out can nevertheless be observed. These observations suggest that weaker interactions between the PCL matrix and the PLA fibers

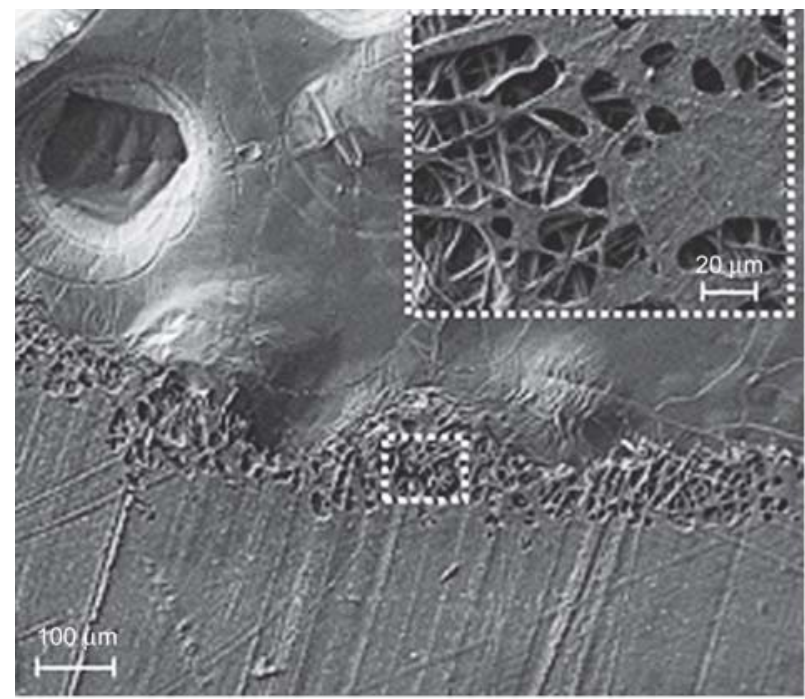

a) were established when reinforced films were derived from the single electrospinning (i.e. higher deformation and fiber pull-out were detected).

\subsection{CHX load and release from PCL films reinforced with PLA}

Electrospinning conditions were varied for two reasons. First, because the electrospinning solvent for PLA was modified by addition of dimethyl sulfoxide to the acetone- $\mathrm{CHCl}_{3}$ mixture in order to allow dissolution of CHX. Second, because the voltage for PCL had to be reduced from 30 to $22.5 \mathrm{kV}$ when flow rates under $15 \mathrm{~mL} / \mathrm{min}$ were required. In all cases, homogeneous fibers with similar characteristics to those obtained from unloaded samples were obtained. Specifically, no significant differences between diameters of loaded and unloaded PLA microfibers were detected (i.e. diameters varied in the $1.2-1.7 \mu \mathrm{m}$ range). Table 4 shows that the mechanical properties of CHX loaded samples follow the above trends. A slight decrease of modulus and tensile strength compared to the related unloaded samples is always observed, but it is clear that these values are still higher than those found for unloaded PCL films.

CHX release was evaluated for samples prepared by single and dual electrospinning, as well by loading of the drug into one (PLA or PCL) or both polymers, as shown in Figure 11. Typical release profiles can be seen in Figure 12 for representative C-PLA/PCL-20 and PLA/PCL-20 samples. Note that samples with slightly different PLA ratios (i.e. from 10 to $30 \mathrm{wt} \%$ )

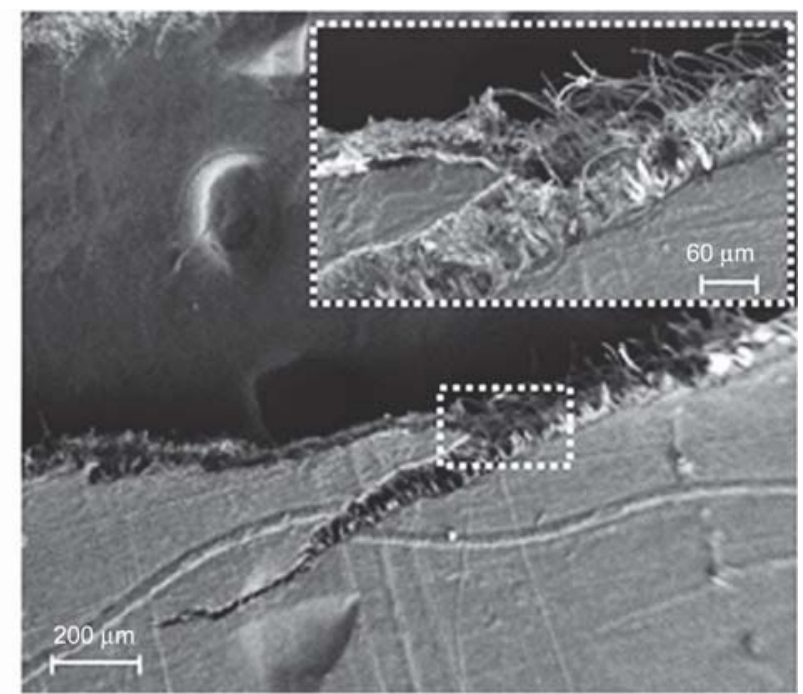

b)

Figure 10. SEM micrographs showing the fracture surface of PCL samples reinforced with PLA microfibers prepared from co-electrospun mats (a) and by molding between PCL films (b). Images are provided together with specific details (insets). 


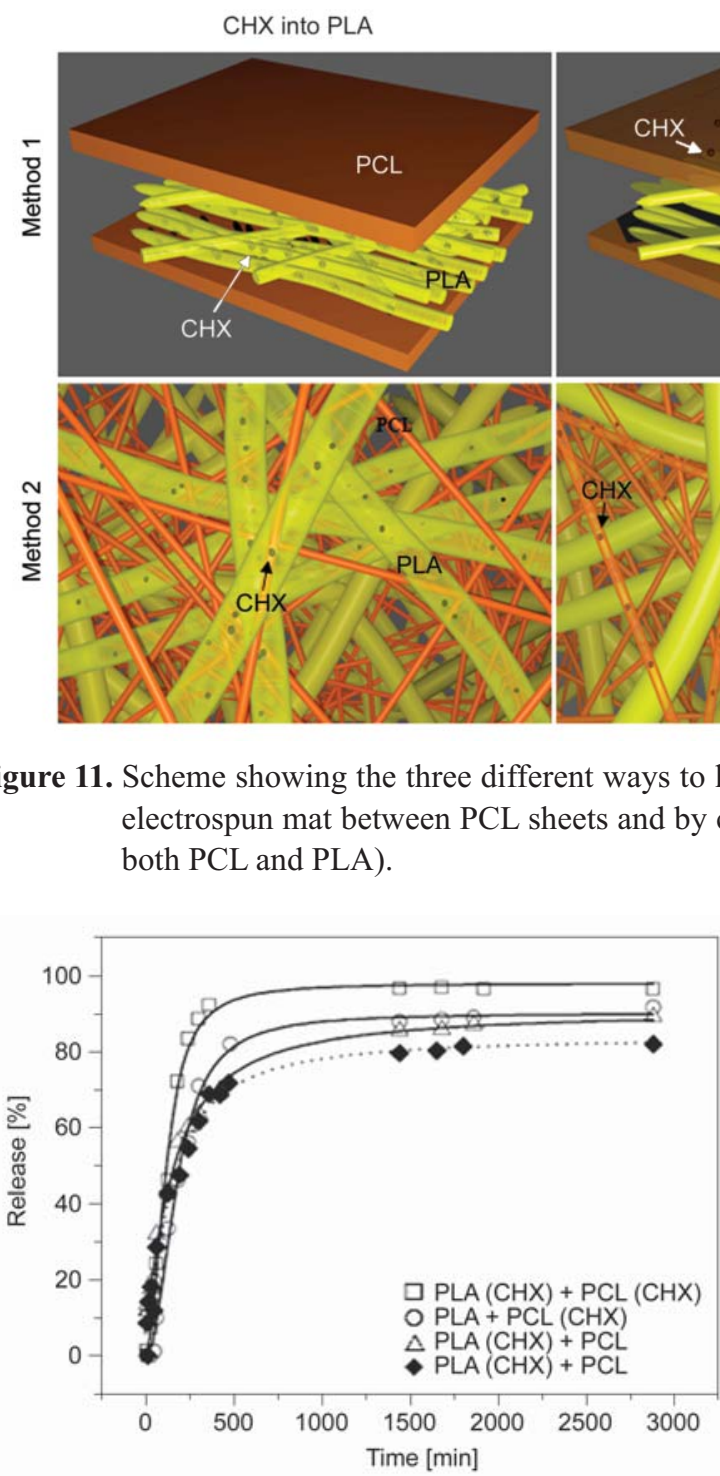

Figure 12. CHX release profiles of PCL matrices containing a theoretical PLA weight percentage of $20 \%$. Empty symbols correspond to samples prepared from co-electrospun mats, whereas full symbols correspond to samples prepared by molding the PLA electrospun mat between two PCL sheets.

behave similarly. Main release data are summarized in Table 5. Some relevant observations can be made:

a) Release is always characterized by a fast step that could be fitted (i.e. the regression coefficient is always higher than 0.97) with a typical Higuchi equation (Equation (2)) initially conceived for planar geometries [36, 37]:

$\frac{M_{\mathrm{t}}}{M_{0}}=k_{\mathrm{H}} t^{1 / 2}$

where $k_{\mathrm{H}}$ is the Higuchi release constant, $M_{\mathrm{t}}$ is the percentage of drug released at time $t$, and $M_{0}$ is the maximum percentage of released drug.
Table 5. Release data corresponding to the different loaded samples $^{\mathrm{a}}$

\begin{tabular}{|l|l|c|c|r|}
\hline \multicolumn{1}{|c|}{ Sample } & $\begin{array}{c}\text { Polymer where } \\
\text { CHX was loaded }\end{array}$ & $\begin{array}{c}\boldsymbol{k}_{\mathbf{H}} \\
{\left[\mathbf{h}^{\mathbf{- 0 . 5}}\right]}\end{array}$ & $\begin{array}{c}\text { CHX released } \\
{[\mathbf{6}]}\end{array}$ & $\begin{array}{c}\boldsymbol{t}_{\mathbf{9}^{\mathbf{c}}} \\
{[\mathbf{m i n}]}\end{array}$ \\
\hline C-PLA/PCL & PLA & 0.39 & 89 & 1500 \\
\hline C-PLA/PCL & PCL & 0.46 & 91 & 550 \\
\hline C-PLA/PCL & PLA + PCL & 0.47 & 95 & 400 \\
\hline PLA/PCL & PLA & 0.28 & 85 & 1800 \\
\hline PLA/PCL & PCL & 0.47 & 95 & 500 \\
\hline PLA/PCL & PLA + PCL & 0.48 & 97 & 400 \\
\hline
\end{tabular}

${ }^{a}$ Values are averaged over the three compositions since no significant differences were found between them.

bPercentage delivered after 3000 minutes of exposure to the release medium.

${ }^{\mathrm{c}}$ Time required to achieve a release of $97 \%$ with respect to the value achieved after 3000 minutes of exposure to the release medium.

b) Higuchi constant was lower when only PLA electrospun fibers were loaded with CHX since the drug diffusion pathway was increased compared to samples with the drug loaded into the PCL matrix. In the same sense, release was faster for samples prepared by co-electrospinning since PLA fibers were better distributed/mixed inside the PCL matrix, and consequently the pathway was reduced.

c) In all cases, a slight percentage of the loaded drug was effectively encapsulated into the reinforced films at least during an exposure to the release medium of up to $3000 \mathrm{~h}$. This retention was significant (i.e. 15 and 11\%) for samples having only CHX loaded into the PLA microfibers. Logically, the lower retention was found for samples prepared by co-electrospinning. 
d) Significant differences in the time required to reach the maximum release were detected when only CHX was loaded into the PLA microfibers. Thus, 1500-1800 min was determined for these samples, whereas this period decreased to 400 550 min when PCL was also loaded.

\subsection{Antibacterial activity of PCL films} reinforced with PLA and loaded with CHX Bacterial growth inhibition of E. coli and S. epidermidis is shown in Figures 13, respectively. The behavior of unloaded samples prepared by co-electrospinning and single electrospinning against the selected Gram+ and Gram- bacteria was similar to that of the control. Typical curves with a lag phase (approximately $4 \mathrm{~h}$ ), a log phase indicative of exponential growth (up to 8-9 h of culture) and a final stationary phase beyond $24 \mathrm{~h}$ were observed. On the contrary, all samples loaded with CHX showed a complete inhibition of bacterial growth, with the exception of samples where CHX was loaded in the PLA microfibers only. In any case, the worst situation (S. epidermidis) corresponded to a maximum bacterial growth of only $5 \%$ with respect to the control, and could therefore be considered insignificant. The result,

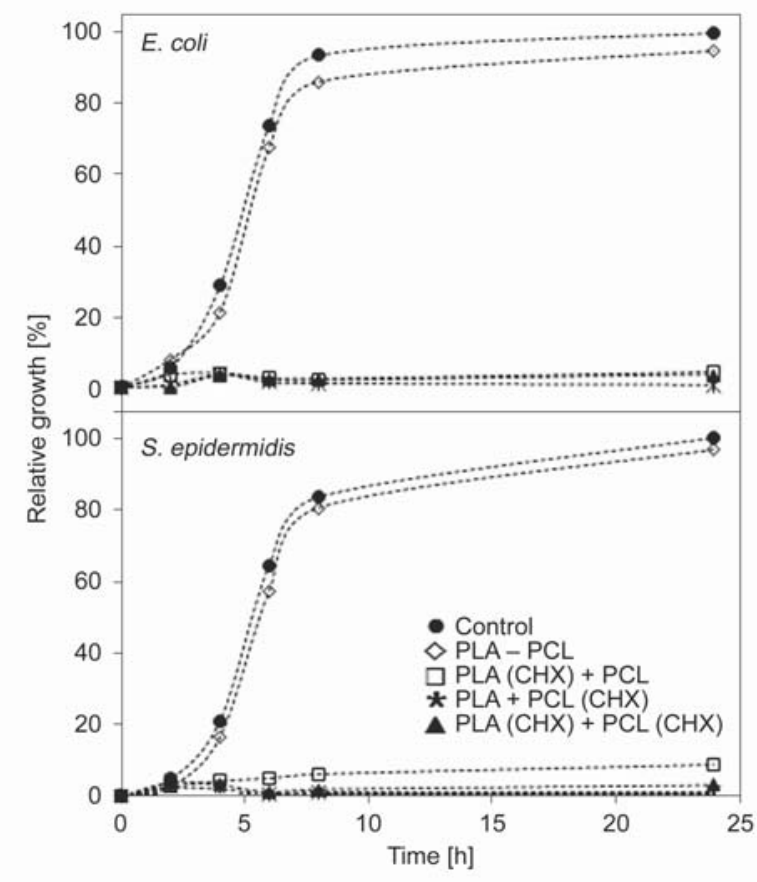

Figure 13. Relative growth of E. coli and S. epidermidis in control, unloaded and CHX loaded samples containing $20 \mathrm{wt} \%$ of PLA microfibers. Reinforced polymer samples were prepared by co-electrospinning. however, clearly indicates the greater difficulty of CHX to diffuse in this fabric configuration.

Similar qualitative results were obtained from the observation of inhibition halos (Figure 14). It is clear that CHX loaded in the PLA microfibers only diffused easily through PCL layers. It should be pointed out that inhibition halos were always homogeneous around the films plates, indicating a good distribution of the drug during the preparation method. Finally, Figure 14 indicates that the size of the halos varied according to the polymer into which CHX was loaded, decreasing in the order: PCL+PLA > PCL > PLA. On the other hand, halos were highly similar for the two preparation methods (i.e. single and dual electrospinning).

Figure 15 shows the results of bacterial adhesion after $24 \mathrm{~h}$ of incubation in broth culture medium. Note that measurements indicated residual bactericide activity after a previous inhibition of $24 \mathrm{~h}$. It is clear that unloaded specimens are highly susceptible to be colonized by both kinds of bacteria, whereas a different sensitivity of loaded films towards bacteria was observed. The highest infection rate (ca. 80\%) was found when CHX was only incorporated in the reinforcing PLA microfibers only, intermediate infection rate when only the PCL matrix was loaded (ca. 60\%) and the lowest rate when CHX was loaded into both polymers (ca. 40\%). In general, $\mathrm{CHX}$ was found to be most effective against $E$. coli, but no significant differences were detected according to the preparation method (single or dual electrospinning) or even according to the ratio of PLA microfibers incorporated into the PCL matrix.

\section{Conclusions}

PCL films reinforced with PLA microfibers could be effectively prepared by a co-electrospinning procedure that rendered clear advantages in terms of crystallinity and mechanical properties compared to typical molding of PLA microfibers between films of the PCL matrix. The proposed procedure improved interaction between PLA fibers and the PCL matrix, with cold crystallization of PLA being favored during the molding process. The incorporation of PLA microfibers could compensate for the loss of mechanical properties caused by the incorporation of small drugs into PCL matrices and even improve the final performance of the material. 


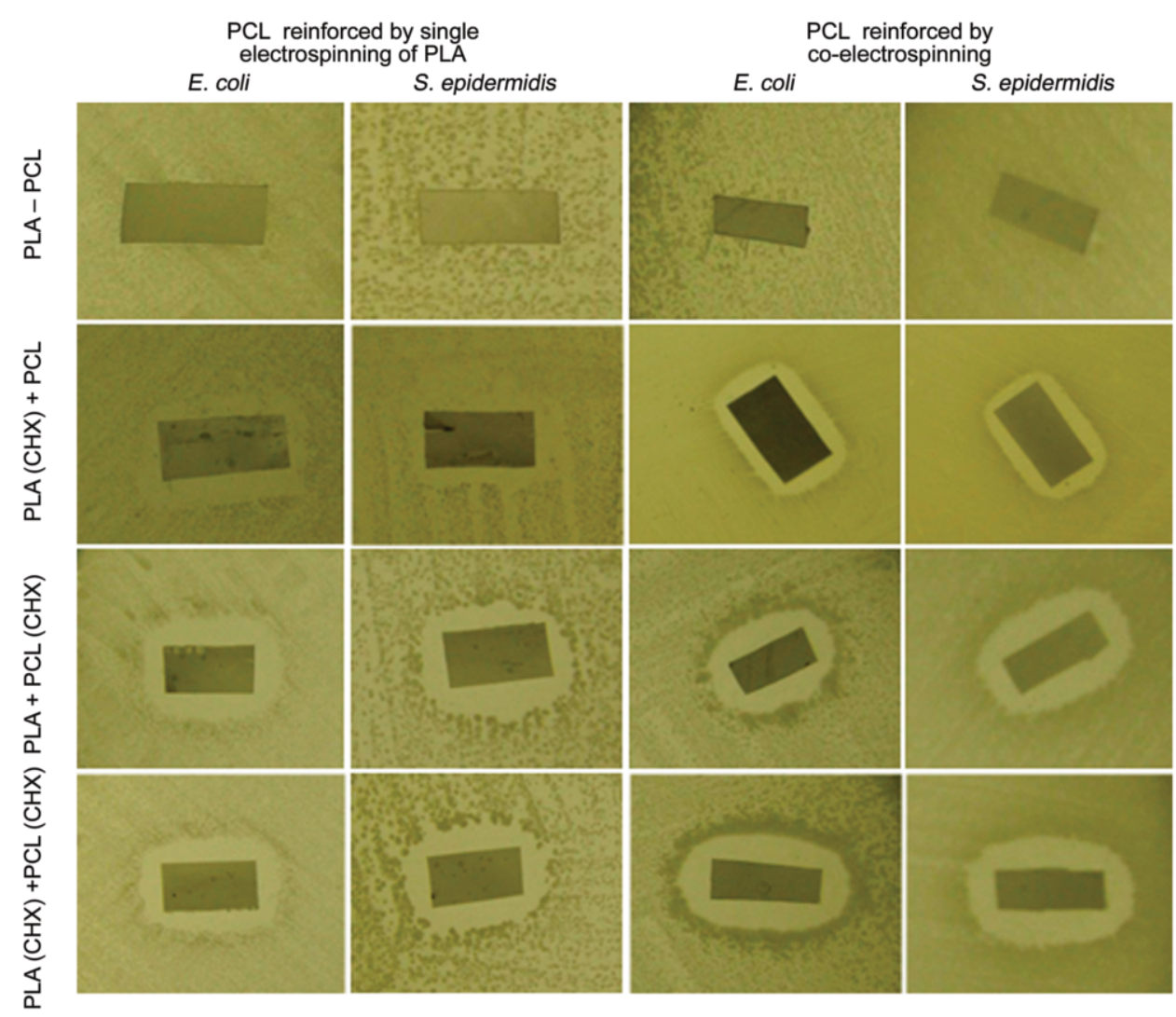

Figure 14. Images showing the inhibition halos on agar plates seeded with E. coli and S. epidermidis for samples unloaded and CHX loaded samples and prepared from co-electrospun mats and by molding the PLA electrospun mat between two PCL sheets. Results of the different ways of incorporating the bactericide drug are also shown.

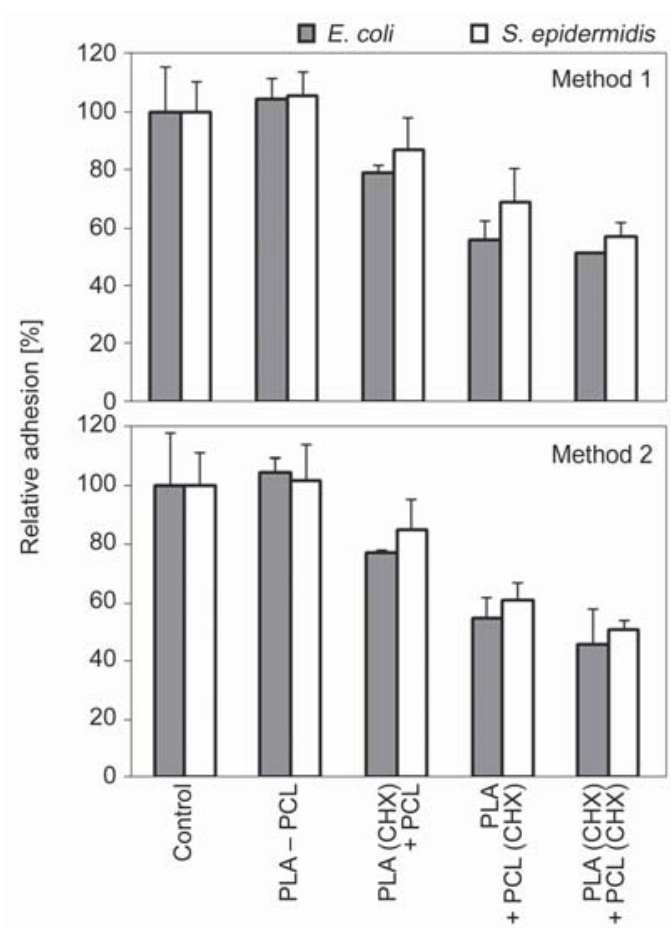

Figure 15. Results of bacterial adhesion assays performed on $10 \mathrm{wt} \%$ PLA reinforced samples prepared from co-electrospun PLA and PCL fibers (method 2) and by molding a PLA fibrous mat between two PCL films (method 1).
The co-electrospinning procedure allowed bactericide agents like chlorhexidine to be easily loaded into both polymers. However, a slower release rate and a high retention were observed when the drug was only loaded into the PLA fibers. Slight differences were again detected between the two preparation methods; specifically, films prepared by co-electrospinning showed a faster release. A bactericide effect against Gram+ and Gram- bacteria was demonstrated for all CHX loaded samples despite the high susceptibility of both polymers to be colonized. Antibacterial activity was still highly significant under the worst release conditions (i.e. samples prepared by single electrospinning and loaded only into the PLA fibers).

\section{Acknowledgements}

Authors are in debt to supports from MINECO and FEDER (MAT2015-69547-R) and the Generalitat de Catalunya (2014SGR188). The work has also been carried out under a research agreement between B. Braun Surgical, S. A. and the Universitat Politècnica de Catalunya. Dr. Y. Márquez thanks financial support from B. BRAUN Surgical S.A. Diffraction experiments were performed at NCD beamline at ALBA Synchrotron with the collaboration of ALBA staff. 


\section{References}

[1] Reneker D. H., Chun I.: Nanometre diameter fibres of polymer, produced by electrospinning. Nanotechnology, 7, 216-223 (1996).

https://doi.org/10.1088/0957-4484/7/3/009

[2] Reneker D. H., Yarin A. L., Fong H., Koombhongse S.: Bending instability of electrically charged liquid jets of polymer solutions in electrospinning. Journal of Applied Physics, 87, 4531-4547 (2000).

https://doi.org/10.1063/1.373532

[3] Frenot A., Chronakis I. S.: Polymer nanofibers assembled by electrospinning. Current Opinion in Colloid and Interface Science, 8, 64-75 (2003).

https://doi.org/10.1016/S1359-0294(03)00004-9

[4] Dzenis Y.: Spinning continuous fibers for nanotechnology. Science, 304, 1917-1919 (2004).

https://doi.org/10.1126/science.1099074

[5] Li D., Xia Y.: Electrospinning of nanofibers: Reinventing the wheel? Advanced Materials, 16, 1151-1170 (2004).

https://doi.org/10.1002/adma.200400719

[6] Jayaraman K., Kotaki M., Zhang Y., Mo X., Ramakrishna S.: Recent advances in polymer nanofibers. Journal of Nanoscience and Nanotechnology, 4, 52--65 (2004).

[7] Dhakate S. R., Singla B., Uppal M., Mathur R. B.: Effect of processing parameters on morphology and thermal properties of electrospun polycarbonate nanofibers. Advanced Materials Letters, 1, 200-204 (2010). https://doi.org/10.5185/amlett.2010.8148

[8] Sharma S.: Ferroelectric nanofibers: Principle, processing and applications. Advanced Materials Letters, 4, 522-533 (2013).

https://doi.org/10.5185/amlett.2012.9426

[9] Dersch R., Steinhart M., Boudriot U., Greiner A., Wendorff J. H.: Nanoprocessing of polymers: Applications in medicine, sensors, catalysis, photonics. Polymers for Advanced Technologies, 16, 276-282 (2005).

https://doi.org/10.1002/pat.568

[10] Chronakis I. S.: Novel nanocomposites and nanoceramics based on polymer nanofibers using electrospinning process - A review. Journal of Materials Processing Technology, 167, 283-293 (2005).

https://doi.org/10.1016/j.jmatprotec.2005.06.053

[11] Deitzel J. M., Kleinmeyer J., Harris D., Beck Tan N. C.: The effect of processing variables on the morphology of electrospun nanofibers and textiles. Polymer, 42, 261-272 (2001).

https://doi.org/10.1016/S0032-3861(00)00250-0

[12] Tiwari A., Terada D., Yoshikawa C., Kobayashi H.: An enzyme-free highly glucose-specific assay using selfassembled aminobenzene boronic acid upon polyelectrolytes electrospun nanofibers-mat. Talanta, 82, 1725 1732 (2010).

https://doi.org/10.1016/j.talanta.2010.07.078
[13] Bergshoef M. M., Vancso G. J.: Transparent nanocomposites with ultrathin, electrospun nylon-4,6 fiber reinforcement. Advanced Materials, 11, 1362-1365 (1999). https://doi.org/10.1002/(SICI)15214095(199911)11:16<1362::AID-ADMA1362>3.0.CO;2-X

[14] Fong H.: Electrospun nylon 6 nanofiber reinforced BISGMA/TEGDMA dental restorative composite resins. Polymer, 45, 2427-2432 (2004).

https://doi.org/10.1016/j.polymer.2004.01.067

[15] Pinho E. D., Martins A., Araújo J. V., Reis R. L., Neves N. M.: Degradable particulate composite reinforced with nanofibres for biomedical applications. Acta Biomaterialia, 5, 1104-1114 (2009).

https://doi.org/10.1016/j.actbio.2008.11.018

[16] del Valle L. J., Díaz A., Royo M., Rodríguez-Galán A., Puiggalí J.: Biodegradable polyesters reinforced with triclosan loaded polylactide micro/nanofibers: Properties, release and biocompatibility. Express Polymer Letters, 6, 266-282 (2012).

https://doi.org/10.3144/expresspolymlett.2012.30

[17] Neppalli R., Marega C., Marigo A., Bajgai M. P., Kim H. Y., Causin V.: Improvement of tensile properties and tuning of the biodegradation behavior of polycaprolactone by addition of electrospun fibers. Polymer, 52, 4054-4060 (2011).

https://doi.org/10.1016/j.polymer.2011.06.039

[18] Neppalli R., Marega C., Marigo A., Bajgai M. P., Kim H. Y., Causin V.: Poly(E-caprolactone) filled with electrospun nylon fibres: A model for a facile composite fabrication. European Polymer Journal, 46, 968-976 (2010). https://doi.org/10.1016/j.eurpolymj.2010.01.004

[19] Neppalli R., Marega C., Marigo A., Bajgai M. P., Kim H. Y., Ray S. S., Causin V.: Electrospun nylon fibers for the improvement of mechanical properties and for the control of degradation behavior of poly(lactide)-based composites. Journal of Materials Research, 27, 13991409 (2012).

https://doi.org/10.1557/jmr.2012.70

[20] Molnár K., Koštáková E., Mészáros L.: The effect of needleless electrospun nanofibrous interleaves on mechanical properties of carbon fabrics/epoxy laminates. Express Polymer Letters, 8, 62-72 (2014). https://doi.org/10.3144/expresspolymlett.2014.8

[21] Chen L., Bromberg L., Hatton T. A., Rutledge G. C.: Electrospun cellulose acetate fibers containing chlorhexidine as a bactericide. Polymer, 49, 1266-1275 (2008). https://doi.org/10.1016/j.polymer.2008.01.003

[22] del Valle L. J., Roa M., Díaz A., Casas M. T., Puiggalí J., Rodríguez-Galán A.: Electrospun nanofibers of a degradable poly(ester amide). Scaffolds loaded with antimicrobial agents. Journal of Polymer Research, 19, 9792-9805 (2012).

https://doi.org/10.1007/s10965-011-9792-2 
[23] Fernandes J. G., Correia D. M., Botelho G., Padrão J., Dourado F., Ribeiro C., Lanceros-Méndez S., Sencadas V.: PHB-PEO electrospun fiber membranes containing chlorhexidine for drug delivery applications. Polymer Testing, 34, 64-71 (2014).

https://doi.org/10.1016/j.polymertesting.2013.12.007

[24] Green J-B. D., Fulghum T., Nordhaus M. A.: Immobilized antimicrobial agents: A critical perspective. in 'Science against microbial pathogens: Communicating current research and technological advances' (ed.: Méndez-Vilas A.), Badajoz, Formatex, 84-98 (2011).

[25] Cailloux J., Santana O. O., Franco-Urquiza E., Bou J. J., Carrasco F., Gamez-Perez J., Maspoch M. L.: Sheets of branched poly(lactic acid) obtained by one step reactive extrusion calendering process: Melt reology analysis. Express Polymer Letters, 7, 304-318 (2013). https://doi.org/10.1007/s10853-014-8101-y

[26] Llorens E., Calderón S., del Valle L. J., Puiggalí J.: Polybiguanide (PHMB) loaded in PLA scaffolds displaying high hydrophobic, biocompatibility and antibacterial properties. Materials Science and Engineering: C, 50, 74-84 (2015).

https://doi.org/10.1016/j.msec.2015.01.100

[27] Barua B., Saha M. C.: Investigation on jet stability, fiber diameter, and tensile properties of electrospun polyacrylonitrile nanofibrous yarns. Journal of Applied Polymer Science, 132, 41918/1-41918/11 (2015)

https://doi.org/10.1002/APP.41918

[28] Wunderlich B.: Macromolecular physics, Volume 3: Crystal melting. Academic Press, New York (1980).

[29] Fischer E. W., Sterzel H. J., Wegner G.: Investigation of the structure of solution grown crystals of lactide copolymers by means of chemical reactions. Kolloid-Zeitschrift und Zeitschrift für Polymere, 251, 980-990 (1973). https://doi.org/10.1007/BF01498927
[30] Chatani Y., Okita Y., Tadokoro H., Yamashita Y.: Structural studies of polyesters. III. Crystal structure of poly$\varepsilon$-caprolactone. Polymer Journal, 1, 555-562 (1970). https://doi.org/10.1295/polymj.1.555

[31] Iwata T., Doi Y.: Morphology and enzymatic degradation of poly( $\varepsilon$-caprolactone) single crystals: Does a polymer single crystal consist of micro-crystals? Polymer International, 51, 852-858 (2002).

https://doi.org/10.1002/pi.858

[32] De Santis P., Kovacs A. J.: Molecular conformation of poly(S-lactic acid). Biopolymers, 6, 299-306 (1968). https://doi.org/10.1002/bip.1968.360060305

[33] Hoogsteem W., Postema A. R., Pennings A. J., Brinke G. T., Zugenmaier P.: Crystal structure, conformation and morphology of solution-spun poly(L-lactide) fibers. Macromolecules, 23, 634-642 (1990). https://doi.org/10.1021/ma00204a041

[34] Baji A., Mai Y-W., Wong S-C., Abtahi M., Chen P.: Electrospinning of polymer nanofibers: Effects on oriented morphology, structures and tensile properties. Composites Science and Technology, 70, 703-718 (2010). https://doi.org/10.1016/j.compscitech.2010.01.010

[35] Lu J-W., Zhang Z-P., Ren X-Z., Chen Y-Z., Yu J., Guo Z-X.: High-elongation fiber mats by electrospinning of polyoxymethylene. Macromolecules, 41, 3762-3764 (2008). https://doi.org/10.1021/ma702881k

[36] Higuchi T.: Mechanism of sustained action medication. Theoretical analysis of rate of release of solid drugs dispersed in solid matrices. Journal of Pharmaceutical Sciences, 52, 1145-1149 (1963). https://doi.org/10.1002/jps.2600521210

[37] Baker R. W.: Controlled release of biologically active agents. Wiley, New York (1987). 